\title{
Predicting outcome in term neonates with hypoxic-ischaemic encephalopathy using simplified MR criteria
}

Rajeev Jyoti • Ross O’Neil • Elizabeth Hurrion

Published online: 3 January 2007

(C) Springer-Verlag 2007

The online version of the original article can be found at http://dx.doi. Elizabeth Hurrion was omitted from the list of authors. org/10.1007/s00247-005-0024-y.

R. Jyoti $(\bowtie) \cdot$ R. O’Neil

Medical Imaging, The Canberra Hospital,

Yamba Drive, Garran,

Canberra 2605 ACT, Australia

e-mail: Rajeev_Jyoti@act.gov.au

E. Hurrion

Department of Neonatology, Mater Mother's Hospital,

South Brisbane, Queensland 4101, Australia 